\title{
INFLUENCIA DE LAAURENCE STERNE EN LA LITERATURA HISPANOAMERICANA CONTEMPORÁNEA
}

Fernando Toda

Como lector aficionado a la literatura hispanoamericana y estudioso de la obra de Laurence Sterne (1713-1768), me resulta interesante observar la influencia que, directa o indirectamente, parece haber ejercido el genial humorista británico sobre ciertos escritores de Hispanoamérica. El ejemplo más reciente lo encuentro en la última novela de Carlos Fuentes, Cristobal Nonato, publicada en 1987. En este libro, del que me ocuparé al final del presente trabajo, hay varios elementos que evocan la narrativa sterneana, y el propio autor así lo ha reconocido en diversas charlas y entrevistas concedidas a raíz de su publicación. Pero, como ya he indicado, el de Fuentes es para mí tan sólo el caso más reciente. Creo, en efecto, que en la obra de varios de los autores que integran la extraordinaria generación de narradores hispanoamericanos que empezó a ser conocida en España en la década de 1960 se puede detectar la huella de Sterne, y más concretamente de su obra maestra, The Life and Opinions of Tristram Shandy, Gentleman, publicada en nueve volúmenes entre 1759 y 1767 . En las páginas que siguen, pretendo solamente ofrecer algunos ejemplos de cómo se pueden encontrar ecos de Tristram Shandy en escritores tan destacados de esa generación como Cortázar, Borges, Lezama Lima o Cabrera Infante.

Con motivo de la muerte de Julio Cortázar a principios de 1984, el crítico español José María Alfaro escribía las siguientes líneas en un breve artículo de homenaje:

El deslumbramiento producido por su novela Rayuela provino del planteamiento para la búsqueda de un distinto tipo de lector: el lector cómplice frente al habitual y pasivo lector hembra. El experimentalismo de Cortázar persigue el esfuerzo de la colaboración ${ }^{1}$. 
Este tipo de escritura que pretende involucrar al lector resultaba un tanto deslumbrante, en efecto, por rebasar las expectativas habituales de los lectores de novelas. Sin embargo, por lo que se refiere a la novedad de esa técnica, la explicación de Alfaro hace que quien conozca Tristram Shandy piense inmediatamente en esa obra, sobre la cual se han vertido opiniones como la que sigue, recogida del crítico británico David Daiches:

El tono sugerente, las llamadas al lector... los asteriscos y espacios en blanco para que el lector los interprete y rellene como desee, también sirven para implicarle en la novela. Se convierte al lector en conspirador con el autor para producir la obra ${ }^{2}$.

Parece pues, que en este aspecto Cortázar tiene, cuando menos, un precursor en Sterne, y seguramente podemos hablar de una influencia directa, ya que el escritor argentino conocía Tristram Shandy, novela que aparece citada en $L a$ vuelta al día en ochenta mundos (1967). Allí, además, Cortázar nos proporciona una pista para descubrir la posible influencia de Sterne en otro autor hispanoamericano, José Lezama Lima. Cortázar evoca la obra de Sterne a propósito de la novela Paradiso:

No sé si Lezama vio que el desarrollo inicial del tema llevaría a pensar con gran regocijo en Tristram Shandy, pues si bien José Cemí ya está vivo al comienzo del relato, y en cambio Tristram, que cuenta su propia vida, ni siquiera ha nacido a mitad del libro, es evidente que el protagonista en torno al cual se organiza Paradiso, queda en la penumbra mientras el libro avanza ${ }^{3} .$.

En esa obra de Cortázar, el pequeño dibujo de una mano que señala ciertos párrafos es el mismo recurso tipográfico que podemos encontrar en las páginas de Tristram Shandy.

Lo que Cortázar, Lezama y otros autores hispanoamericanos parecen haber recogido de Sterne es, sobre todo, la técnica. Las innovaciones de Sterne, tan criticadas por el Doctor Johnson en el propio siglo XVIII, parecen haberles servido de impulso para experimentar con la escritura. La nueva narrativa que surge en Hispanoamérica en nuestro siglo pudo encontrar en el estilo de Sterne algunos elementos que sirvieron para desarrollar un nuevo modo de expresión literaria.

En el artículo antes citado, J. M. Alfaro relacionaba a Cortázar con otro gran escritor argentino, Jorge Luis Borges, si bien señalaba que ambos escritores siguieron luego caminos diferentes. "Cortázar empalma directamente con Borges, el antecedente cierto de infinitas aventuras y peripecias intelectuales», escribía el crítico, y cabe preguntarse con quién, o con qué tradición, entronca, a su vez, Jorge Luis Borges. A mi entender, en algunos aspectos también él puede recordar a Sterne. En el prólogo a El jardín de los senderos que se bifurcan (1941), haciendo alusión a un artificio muy querido por él, como es el de citar a autores ficticios, Borges escribía:

2 David Daiches, A Critical History of English Literature, vol. III (London: Secker \& Warburg, 1969), p. 733. (La traducción de la cita es mía).

3 Julio Cortázar, La vuelta al día en ochenta mundos, tomo II (Madrid: Siglo XXI de España, 1984), p. 58. 
Desvarío laborioso y empobrecedor el de componer vastos libros... Mejor procedimiento es simular que esos libros ya existen y ofrecer un resumen, un comentario. Así procedı́ Carlyle en Sartor Resartus; así Butler en The Fair Haven ${ }^{4}$...

Podríamos añadir que así procedió Laurence Sterne, por ejemplo en los volúmenes III y IV de Tristram Shandy, al hablarnos de la ingente obra de Hafen Slawkenbergius, autor imaginario de obras escritas en latín. Sterne nos facilita, incluso, la versión inglesa de un cuento de Slawkenbergius, proporcionándonos, además, a lo largo de tres páginas confrontadas como una edición bilingüe, la «versión original latina», y añade una breve nota «erudita», que reproduzco aquí traducida:

Puesto que Hafen Slawkenbergius de Nasis es obra extremadamente difícil de encontrar, quizaś sea de interés para el lector culto poder ver algunas páginas del original a modo de muestra. No haré ninguna reflexión sobre él salvo que el latín narrativo de Slawkenbergius es mucho más conciso que el que emplea para la filosofía, y, mi entender, goza de una mayor latinidad ${ }^{5}$.

Por lo que se refiere a este recurso literario, naturalmente no exclusivo de Sterne ni original de él, tal vez resulte posible atribuir a influencia sterneana su utilización por Borges. Este cita a Carlyle (1795-1881), escritor inglés que, seguramente, conocería la obra de Sterne, pero, en todo caso, se puede apuntar una influencia indirecta de Sterne en Carlyle: Sartor Resartus (1834) es una obra en la que resulta perceptible la influencia del autor alemán Jean Paul Richter (1763-1825), muy admirado por Carlyle. A propósito de Richter, Menéndez Pelayo decía que era «discípulo de Swift, de Sterne, de Fielding, y de todos los grandes humoristas ingleses» ${ }^{6}$.

Así pues, podemos argumentar que, aunque fuera tan sólo de forma secundaria, la influencia de Sterne llegó hasta Borges. Desconozco si Borges ha dejado constancia explícita de su conocimiento de la obra de Sterne, pero, dada su gran afición a la literatura inglesa, me inclino a pensar que es poco probable que le pasara inadvertida. Otro dato que parece reforzar esta impresión lo constituye el hecho de que, en al menos dos ocasiones, Borges alude a Robert Burton, uno de los autores favoritos de Sterne, cuya influencia de deja sentir en Tristram Shan$d y^{7}$. Burton aparece citado en el prólogo a El libro de los seres imaginarios ${ }^{8} \mathrm{y}$

4 Jorge Luis Borges, Ficciones (Madrid: Alianza Emecé, 1971), p. 12.

5 Nota de Sterne al cuento de Slawkenbergius, con el que empieza el volumen IV. Esta traducción está tomada de Vida y opiniones del caballero Tristram Shandy (edición de Fernando Toda) traducción de J. A. López de Letona, Madrid: Cátedra, 1985), p. 276.

6 Marcelino Menéndez Pelayo, Historia de las ideas estéticas en España, tomo IV (Santander: Aldus, 1940), p. 110.

7 Robert Burton (1577-1640), clérigo, publicó en 1621 The Anatomy of Melancholy, tratado que pretendía ser médico pero que, debido a la gran cantidad de apoyos literarios empleados por el autor para sus argumentos, resulta más bien un compendio de saberes bien dispares. En el primer capítulo del volumen V de Tristram Shandy, Sterne se queja de los escritores que plagian a otros, utilizando palabras tomadas de esta obra de Burton que, en esa ocasión, no cita.

8 Jorge Luis Borges, El libro de los seres imaginarios (Barcelona: Bruguera, 1980), p. 5. 
una cita tomada de su obra La anatomía de la melancolía encabezada la ficción de «La biblioteca de Babel» ${ }^{9}$.

Muchos de los escritores hispanoamericanos de la segunda mitad de este siglo han sido grandes admiradores de la literatura en lengua inglesa. Ya es conocida, por ejemplo, la influencia de Faulkner en García Márquez, y creo que - sobre todo en lo que se refiere al aspecto formal- conviene tener presente que la obra de Sterne parece haber figurado entre las lecturas de bastantes de ellos. En mi opinión, ése es el caso de Guillermo Cabrera Infante. Cuando apareció en España, en 1967, su excelente novela Tres Tristes Tigres, nos llamaron la atención algunos recursos tipográficos, como el de imprimir una página totalmente en negro, emplear distintos tipos de letra dentro del texto, o dejar algunas páginas del libro en blanco. En aquel momento aún no se había publicado ninguna versión española de Tristram Shandy ${ }^{10}$, pero quienes hubieran leído el original reconocerían inmediatamente esos artificios, pues ya habían sido utilizados por Sterne. Los lectores de Tristram Shandy seguramente detectarían también resonancias de esa obra en «El cuento de un bastón seguido de vaya qué correciones de la señora Campbell», pretendida traducción del inglés, con notas, que incluye en su obra el escritor cubano.

Por lo que se refiere a Cristobal Nonato, de Carlos Fuentes, allí las resonancias de Tristram Shandy son múltiples, y perceptibles desde el primer momento, pues ambos libros comienzan con el relato de la concepción del protagonista hecho por él mismo, y en ambos se entrecruzan e intercalan multitud de historias que parecen retrasar el desarrollo de la del propio protagonista. Precisamente sobre el modo de narrar una historia encontramos en Cristóbal Nonato un capítulo (el sexto del libro Cuarto) ${ }^{11}$ que recuerda en más de un aspecto las consideraciones que, como narrador, hace Tristram Shandy sobre el progreso de su obra. Cristóbal escribe:

Esta es la novela que estoy imaginando dentro del huevo de mi madre. (...) Faltaba más, Cristobalito: si la tierra es redonda, por qué no ha de serlo una narración? La línea recta es la distancia más larga entre dos palabras.

Esta comparación de la propia narración con figuras geométricas es muy querida por Sterne, quien, en el capítulo 40 de su volumen VI, nos regala con una serie de dibujos de líneas que ilustran la progresión de cada uno de los cinco volúmenes que ya lleva escritos. Tristram, el narrador, llega incluso a indicarnos por medio de letras impresas sobre la línea correspondiente al quinto volumen, a qué digresiones narrativas corresponden las curvas que aparecen en ella, y señala, con su ironía habitual, que aspira a llegar a una narración representable por medio de una línea recta,invocando a Arquímedes y a los plantadores de coles para soste-

9 Jorge Luis Borges, Ficciones, ed. cit., p. 89.

10 La primera versión española de Tristram Shandy fue la de J. A. López de Letona (Ediciones del Centro, 1975, revisada y reeditada por Cátedra en 1985). Tras ella vinieron las de Ana María Aznar (Planeta, 1976) y Javier Marías (Alfaguara, 1978).

11 Carlos Fuentes, Cristóbal Nonato (Madrid: Fondo de Cultura Económica, 1987), p. 206. 
ner que «la mejor línea es la más corta que se puede trazar entre un punto dado y otro».

Por otra parte, también en lo que atañe al momento elegido para comenzar la narración y al papel del lector, Cristóbal tiene opiniones parecidas a las de Tristram:

Pero si Elector es mi amigo y colaborador, como quiero y confío que / no se detendrá a examinar si esta novela es narrada por mí ab ovo o veinte años después (a la Horacio o a la Dumas) sino que, sea cual sea la premisa, pondrá algo de su parte, será un auxiliar...

Tristram Shandy explica a sus lectores (volumen I, capítulo 4.) que ha decidido iniciar su narración $a b$ Ovo, evocando el comentario de Horacio en su Ars Poetica sobre la obra de Homero. Tanto Sterne como Fuentes juegan con esa expresión en su sentido más literal, pues sus protagonistas-narradores comienzan su historia desde el momento mismo de su concepción. También resulta interesante la alusión a Elector (el lector) como «amigo y colaborador». Nos encontramos de nuevo, y de forma explícita, ante la idea del «lector cómplice» que se desprende de la obra de Cortázar, cuyo antecedente, como hemos visto, se puede encontrar en el tratamiento que da Sterne a sus lectores. El «Elector» a quien se dirige directamente en ese mismo capítulo Cristóbal Nonato equivale al «You, Sir», o «You, Madam» con que Tristram Shandy interpela a sus lectores, a los que obliga a participar en la re-creación de su historia.

Un análisis pormenorizado de esta obra de Carlos Fuentes seguramente pondría de manifiesto otros puntos en común con Tristram Shandy en lo que respecta a la técnica narrativa, a algunos usos del lenguaje y a la reflexión del autor sobre su propia escritura. En cuanto a otros recursos formales como son la tipografía empleada y la composición de las páginas, encontramos numerosos ejemplos que nos recuerdan los artificios empleados ya por Sterne, como pueden ser las exclamaciones u observaciones resaltadas por medio de mayúsculas centradas en una línea aislada, o el montaje escalonado del pasaje de la «escalera rampante» que aparece en el libro Séptimo, capítulo cuarto, o la reproducción del corazón y las letras grabadas en la esclava de la pata de la bestia (libro Octavo, capítulo 15).

Como otros autores hispanoamericanos, Carlos Fuentes ha sabido incorporar parte de la herencia del gran innovador de la novela inglesa del siglo XVIII a las demás raíces de su creación literaria. Un estudio detallado sobre la influencia de Sterne en la literatura hispanoamericana revelaría, tal vez, otros casos en los que el ejemplo de Tristram Shandy ha servido de acicate para la experimentación literaria. Quizás podría ser una buena contribución al análisis de una de las literaturas más ricas de nuestro siglo. 
